\title{
International Union for the Study of Social Insects Report of Secretary-General Joan M. Herbers
}

\section{Annual Report}

(C) International Union for the Study of Social Insects (IUSSI) 2011

This report covers the period January 1, 2010 through December 31, 2010. This was a watershed year for the Union, with the following major events.

- A highly successful Congress in Copenhagen

- Adoption of a new Constitution

- Successful negotiation of a new Contract with our Publisher that will generate significant financial resources for the Union

- ReElection of Officers Johan Billen (Editor-in-Chief), Joan Herbers (Secretary-General), David Nash (Webmaster), and Chris Starr (Archivist).

- Election of Ben Oldroyd as President

\section{Memberships}

I have received no communication whatsoever from sections in Brazil, China, India, Africa, Russia, or Poland. Membership data for the Bolivarian section have not been updated since 2009.

In 2010, I received information from sections as follows:

\begin{tabular}{lcccc}
\hline Section & $\begin{array}{l}\text { Regular } \\
\text { members }\end{array}$ & $\begin{array}{l}\text { Student } \\
\text { members }\end{array}$ & Total & $\begin{array}{l}\text { Change } \\
\text { from 2007 }\end{array}$ \\
\hline Australian & 28 & 11 & 39 & +11 \\
Bolivarian & 25 & 0 & 25 & 0 \\
Central European & 55 & 57 & 112 & +58 \\
French & 62 & 25 & 87 & +25 \\
Italian & 25 & 37 & 62 & +1 \\
Japanese & 26 & 3 & 29 & -10 \\
North American & 137 & 81 & 218 & +79 \\
North-west European & 55 & 64 & 119 & +27 \\
Total & 413 & 278 & 691 & +191 \\
\hline
\end{tabular}

\section{Financial Statement}

The Union's 2010 data below show the Union is in excellent financial health.

Beginning Balance on 1 January 2007.

$\$ 15,742.50$

Income

Capitation and late Fees

$\$ 6,365.00$

Interest.

$\$ 7.28$

Expenditures

Bank Fees

Taxes

Expenses for Congress

$(€ 2,303.19)$

(Hamilton Award, International Committee Business)

Balance on 31 December 2010

$\$ 19,683.61$

Accounts Receivable

$€ 3,500.00$

Accounts Payable

$\$ 50.00$

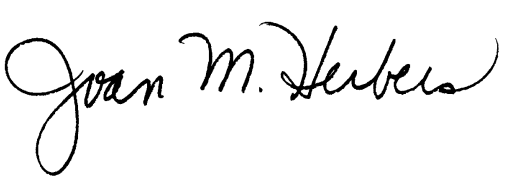

Secretary-General 